\title{
Practical Use of Charcoal as a Remediation Material for Cadmium-polluted Soil
}

\author{
Asa Miura ${ }^{1, *}$, Eisaku Shiratani ${ }^{2}$ \\ ${ }^{1}$ Department of Science and Mathematics Education, University of Fukui, Japan \\ ${ }^{2}$ National Institute for Rural Engineering, Tsukuba city, Japan
}

Copyright $\odot 2018$ by authors, all rights reserved. Authors agree that this article remains permanently open access under the terms of the Creative Commons Attribution License 4.0 International License

\begin{abstract}
The purpose of this study is to examine the practical usage of charcoal as a biomass remediation material for cadmium $(\mathrm{Cd})$ polluted soil in the environment. In the field application of this material, it is necessary to consider handling methods and the environmental impact of the used materials. The following types of experiments were conducted in this study: (1) heavy metals competitive removal in solution, (2) condition of $\mathrm{Cd}$ re-elution from Cd-adsorbed charcoal in solution, and (3) $\mathrm{Cd}$ re-elution from $\mathrm{Cd}$-adsorbed charcoal left in columns of soil and charcoal for long periods. The competitive removals depended on the concentrations of heavy metals. All heavy metals included in the low-level concentration were removed by charcoal efficiently. Although $65-100 \%$ of the $\mathrm{Cd}$ adsorbed by the charcoal was desorbed by strongly acidic water $(\mathrm{pH} 1.5), 0.8-1.6 \%$ was desorbed by water with a $\mathrm{pH}$ of 4.5 , equivalent to the $\mathrm{pH}$ of acidic rain. The $\mathrm{Cd}$ re-elution rates from columns by both acidic and distilled water were low immediately after beginning the experiments and were not detected after two and three months. Therefore, these three experiments demonstrated the possibility of simultaneously removing two or more heavy metals by using the charcoal, processing the contaminated charcoal by using strong acids, and allowing the contaminated charcoal to stay in the environment safely for long periods.
\end{abstract}

Keywords Competitive Adsorption, Heavy Metals, Rainfall Intensity, Re-elution, Used Charcoal

\section{Introduction}

Environmental pollution in Asia has increased along with economic development. During periods of high economic growth, farmland in Japan was contaminated by cadmium $(\mathrm{Cd})$, which is a toxic heavy metal that has diffused in the soil. The soil in several regions in Japan still contains unhealthy levels of this metal. Generally, farmlands are located near industrial land that houses refineries; therefore, $\mathrm{Cd}$ concentrations in the agricultural areas in Japan are higher than those in other countries. That is, toxic heavy metals are included in products themselves and in byproducts. If improper disposal methods, such as illegal waste-dumping or mixing into domestic garbage, are followed, heavy metals could leach into the environment. Toxic heavy metals are dissolved into ions by precipitation and can be discharged into underground water, rivers, or oceans. In particular, because $\mathrm{Cd}$ is easily absorbed by crops, this toxin can enter the human body and bioaccumulate via oral intake of contaminated plants.

To ensure a stable supply of safe foods, it is important for proper farmland standards to be observed and for the health of water/soil environments to be maintained. The $\mathrm{Cd}$ concentration is regulated by the Japanese temporal standard. In addition, countermeasures unrelated to the government standards have been adopted. These include water management methods in wet-rice cultivation, technical methods such as the soil dressing method, and phytoremediation $[1,2]$. Soil-washing technology has also been further studied [3]. In Japan, new, effective technical methods have been discussed for reducing the $\mathrm{Cd}$ concentration in agricultural crops. Current methods for removing heavy metals from solution have been studied. One method involves the use of ion exchange resins [4], whereas another involves the creation of solid-state compounds by ferritization of solutions with high-levels of heavy metals [5-7]. However, because these methods are neither cost effective nor practical, other techniques should be considered.

The development of environmental remediation material with a low environmental impact is one such measure. In this technique, charcoal can be used as a biomass remediation material for Cd-polluted soil in the environment. Recently, some research on metal adsorption from water or soil by biomass has been observed [8-10]. These reports have shown that biochar derived from various materials, such as plant residuals, animal fecal material, and sludge, retain the metals adsorption capacity. 
Wang et al. [11] reported on the repair of heavy metal-contaminated soils with charcoal derived from bamboo, rice hulls, and animal excreta, but when these biochar were applied to the site, problems, such as varying properties with time and the environmental impact of charcoal, have not been discussed. Xu et al. [12] have discussed the adsorption and desorption of charcoal to $\mathrm{Cd}$ in paddy soils. However, it was not assumed that the construction would be carried out on the actual site, and no experiments have been conducted in consideration of weather conditions, such as rainfall.

In our previous study, we proposed a method for enabling the control of $\mathrm{Cd}$ adsorption in farmland soil by using charcoal to protect crops from $\mathrm{Cd}$ contamination; the effects were observed by crop cultivation experiments [13] In the present study, several considerations are addressed in greater detail that must be discussed before this method is adopted for practical use. These factors include competitive adsorption of heavy metals, re-elution from materials containing $\mathrm{Cd}$, and re-elution into the environment due to rainfall when such materials are applied to soil and remain for lengthy periods. In this study, such considerations were investigated and discussed by conducting three laboratory experiments.

\section{Materials and Methods}

\subsection{Adsorbent}

Charcoal was used as the remediation material in the present study because its heavy-metal-adsorption ability was confirmed in our previous experiments [13]. This charcoal was created using thinned cedar wood (Cryptomeria japonica) carbonized at $1050^{\circ} \mathrm{C}$ to produce granules with diameters of $1-5 \mathrm{~mm}$. The $\mathrm{pH}$ level of the charcoal is 8.2 . The physical properties of the charcoal are shown in Table 1.

\subsection{Laboratory Experiments}

\subsubsection{Competitive Removal of Heavy Metals (Experiment} 1)

Metal ions are adsorbed at same site on the adsorbent if the charge number of the ions is the same. Thus, $\mathrm{Cd}$, lead $(\mathrm{Pb})$, copper $(\mathrm{Cu})$, and zinc $(\mathrm{Zn})$ were prepared in aqueous solutions at the following concentration levels: low $(0.02$ $\left.0.5 \mathrm{mg} \mathrm{L}^{-1}\right)$, high (1-10 $\left.\mathrm{mg} \mathrm{L}^{-1}\right)$, and medium $(0.5-5 \mathrm{mg}$ $\left.\mathrm{L}^{-1}\right)$. Each prepared $100 \mathrm{~mL}$ solution was placed into a bottle with $1 \mathrm{~g}$ of charcoal. The solutions were stirred at $125 \mathrm{rpm}$ by using agitation equipment at a constant temperature of $25^{\circ} \mathrm{C}$. The sampling times included the initial solution, $0.25 \mathrm{~h}, 0.5 \mathrm{~h}, 1 \mathrm{~h}, 3 \mathrm{~h}, 12 \mathrm{~h}, 24 \mathrm{~h}$, and $48 \mathrm{~h}$. The samples were immediately filtered by funnels. Highand medium-level-concentration samples were analyzed by atomic emission spectrophotometer (Thermo Fisher
Scientific K.K., iCAP6300Duo View); low-level concentration samples were analyzed by inductively-coupled plasma emission spectrometry (ICP-MS; Perkin Elmer Inc., ELAN DRC- II ).

\subsubsection{Cd re-elusion (Experiment 2)}

Investigation of $\mathrm{Cd}$ concentrations re-eluted from charcoal is necessary if such charcoal that contains traces of $\mathrm{Cd}$ remains in the environment for a lengthy period. Two types of used charcoal were employed in Experiment 2. The first originally held $\mathrm{Cd}$ to determine its adsorption level, and the second held a mixture of $\mathrm{Cd}$ and $\mathrm{Cu}$, also to measure adsorption. To prepare the used charcoal, $3 \mathrm{~g}$ samples were washed by distilled water were placed in a bottle containing $300 \mathrm{~mL}$ of solution containing $1 \mathrm{mg} \mathrm{L}^{-1}$ of $\mathrm{Cd}$ and in another bottle containing both $1 \mathrm{mg} \mathrm{L}^{-1}$ of $\mathrm{Cd}$ and $10 \mathrm{mg} \mathrm{L}^{-1}$ of $\mathrm{Cu}$. The solutions in the bottles were stirred continuously at $125 \mathrm{rpm}$ for $24 \mathrm{~h}$ at $25^{\circ} \mathrm{C} \pm 1{ }^{\circ} \mathrm{C}$. The solutions were then separated into solid and liquid components through funnels. The separated charcoal grains were dried at $80^{\circ} \mathrm{C}$ in a dry oven for $24 \mathrm{~h}$. Thus, the concentrations of the charcoal using $\mathrm{Cd}$ and $\mathrm{Cd} / \mathrm{Cu}$ were made using $0.98 \mathrm{mg} \mathrm{Cd}$ per $1 \mathrm{~g}$ of charcoal and $0.97 \mathrm{mg}$ $\mathrm{Cd}$ and $9.94 \mathrm{mg} \mathrm{Cu}$ per $1 \mathrm{~g}$ charcoal, respectively.

Each type of charcoal was stirred with acidic water prepared at $\mathrm{pH}$ levels of $1.5,3.5,4.5$, and 5.5, in addition to distilled water ( $\mathrm{pH}$ level of 6.8 ), for $1 \mathrm{~h}$. Preliminary experiments revealed no correlation between contact times and $\mathrm{Cd}$ re-elution event. The re-elution events from the charcoal depended on the $\mathrm{pH}$ level rather than stirring time, which explains the relatively short stirring time. After $1 \mathrm{~h}$, the samples were immediately filtered using funnels to begin experiment 2 and were analyzed by an atomic emission spectrophotometer (Thermo Fisher Scientific K.K., iCAP6300Duo View).

\subsubsection{Column Experiment (Experiment 3)}

Investigation of $\mathrm{Cd}$ re-elution affected by rainfall intensity or soil moisture is necessary if the charcoal is applied to the soil. Column experiments were conducted as shown Figure 1. A $1 \mathrm{~cm}, 7 \mathrm{~g}$ layer of charcoal was placed in columns between two $9 \mathrm{~cm}$ layers of soil. We used commercial vegetable cultivation soils in the column experiments. Glass beads were placed at the bottom of column to prevent soil particles from mixing into the water sample. Cd adsorption by the charcoal in this experiment was conducted by a similar method as that in Experiment 2. A $10 \mathrm{~g}$ sample of charcoal was stirred into a $60 \mathrm{mg} \mathrm{L}^{-1} \mathrm{Cd}$ solution at $125 \mathrm{rpm}$ for $24 \mathrm{~h}$ at $25^{\circ} \mathrm{C} \pm 1^{\circ} \mathrm{C}$, and the separated solid Cd-adsorbed charcoal (used charcoal) was employed for the column experiments. 5.94 $\mathrm{mg}$ of $\mathrm{Cd}$ was adsorbed onto the charcoal layer in the column. Drops of water were applied to the soil surface from top of the column. The flow volumes assumed two patterns for rainfall intensity, $10 \mathrm{~mm} \mathrm{~h}^{-1}$ and $100 \mathrm{~mm} \mathrm{~h}^{-1}$, as shown in Table 2. The samples were collected once per 
day during three successive days. Two column equipment sets were prepared according to the respective rainfall intensities. Moreover, samplings under soil moisture conditions were alternately conducted between nonsaturation and saturation conditions for each rainfall intensity condition. $\mathrm{Cd}$ concentrations in the samples were analyzed using an atomic emission spectrophotometer (Thermo Fisher Scientific K.K., iCAP6300Duo View).

Table 1. Physical properties of charcoal used as adsorbent in this study.

\begin{tabular}{|ccccc|}
\hline $\begin{array}{c}\text { Carbonized temperature } \\
\left({ }^{\circ} \mathrm{C}\right)\end{array}$ & $\begin{array}{c}\text { Mean particle diameter } \\
(\mathrm{mm})\end{array}$ & $\begin{array}{c}\text { Mean pore diameter } \\
(\mathrm{nm})\end{array}$ & $\begin{array}{c}\text { Pore volume } \\
\left(\mathrm{ml} \cdot \mathrm{g}^{-1}\right)\end{array}$ & $\begin{array}{c}\text { Specific surface area } \\
\left(\mathrm{m}^{2} \cdot \mathrm{g}^{-1}\right)\end{array}$ \\
1,050 & 1.41 & 2.7 & 0.12 & 224 \\
\hline
\end{tabular}

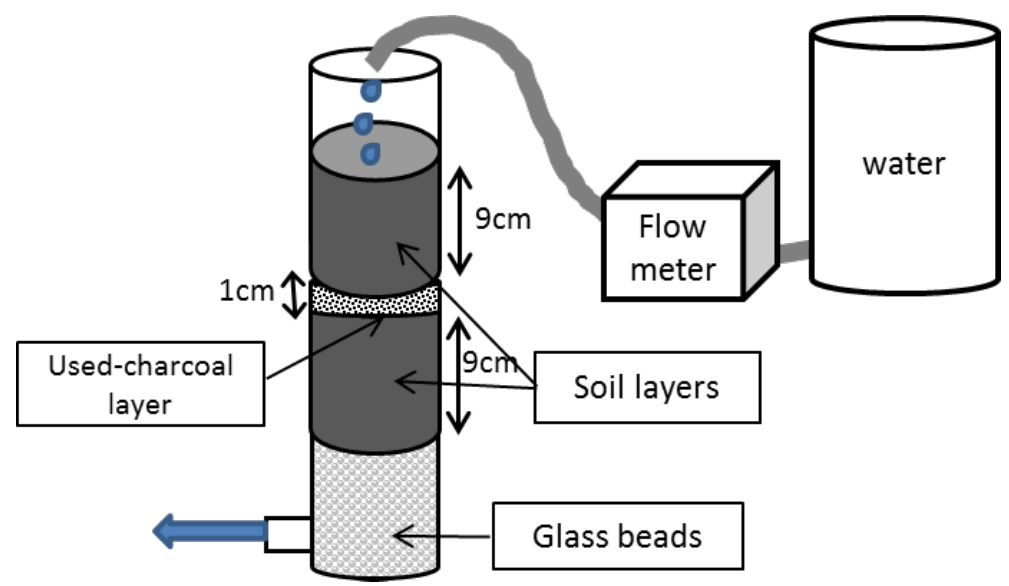

Figure 1. Diagram of column used in Experiment 3.

Table 2. Physical properties of charcoal used as adsorbent in this study.

\begin{tabular}{|c|c|c|}
\hline $\begin{array}{c}\text { Rainfall intensity } \\
\left(\mathrm{mm} \mathrm{h}^{-1}\right)\end{array}$ & a. & b. \\
\hline $\begin{array}{c}{[\text { Flow volume of drops ] }} \\
\left(\mathrm{mL} \mathrm{h}^{-1}\right)\end{array}$ & & \\
\cline { 1 - 2 } 10 & Nonsations of soil layers \\
\hline$\left[\begin{array}{c|c}42] \\
100\end{array}\right]$ & & Saturation \\
\hline
\end{tabular}

\section{Results and Discussion}

\subsection{Competitive Removal of Heavy Metals (Experiment 1)}

Each concentration level of the initial solution for Experiment 1 was prepared as shown Table 3. The competitive removal rates of the heavy metals from the mixed solutions by the charcoal depended on the concentrations of heavy metal ions in the solutions. All ions were effectively removed from the solution containing low-level of heavy metals ions; however, not all the ions were removed from the high-concentration solution. These results are shown in Figures 2 (a) and (b).

After the charcoal was in contact with the solutions containing low-level heavy metal ions for $0.25 \mathrm{~h}$, the removal rate for all types of heavy metals was $80 \%$ (Figure 2(a)). After $48 \mathrm{~h}$, removal rates for heavy metals exceeded $90 \%$. Thus, the charcoal efficiently removed the heavy metals in the low-level concentration.

In the case of the high-level solution, the removal rate for all heavy metals was less than $7 \% 12 \mathrm{~h}$ after beginning the experiment (Figure 2 (b)). The removal rates for $\mathrm{Cu}$ and $\mathrm{Pb}$ rose to $10 \%$ after $24 \mathrm{~h}$, which was maintained through $48 \mathrm{~h}$. Those for $\mathrm{Cd}$ and $\mathrm{Zn}$ were $0 \%$ after $48 \mathrm{~h}$. Moreover, the types of heavy metals mixed in the high-concentration solution were reduced from four elements $(\mathrm{Cd}, \mathrm{Pb}, \mathrm{Cu}$, and $\mathrm{Zn})$ to two $(\mathrm{Cd}$ and $\mathrm{Cu})$. These results indicated that the removal effectiveness of the two heavy metals by charcoal differed from that of the four. The removal rates for both $\mathrm{Cd}$ and $\mathrm{Cu}$ were more than $95 \%$ at $24 \mathrm{~h}$. Further competitive removal experiments should be conducted to consider the differences in concentration patterns. 
The charcoal removed all four heavy metals from the solution with low-level concentration. Conversely, the removal effects of charcoal varied in the high-level solution depending on the types of heavy metals contained in the solution.

The heavy metals removal rates from the solution with medium-level concentration were also determined (Figure 2 (c)). The removal rates for both $\mathrm{Cu}$ and $\mathrm{Pb}$ were approximately $30 \%$, which is a larger percentage than that observed with the high-level concentration. $\mathrm{Cd}$ was removed slightly, and $\mathrm{Zn}$ was not removed at all. These results suggest that threshold solution levels exist for adsorbing all four elements by charcoal.

It is possible for metal ions with equivalent charges to be adsorbed on the same adsorbent between metal ion scramble sites. Machida et al. [14] reported that $\mathrm{Cu}$ and $\mathrm{Pb}$ were competitively adsorbed on the activated carbon from the mixed solution. The decrease in adsorption rate in highly concentrated solutions may be attributed to the area occupied by the heavy metals molecules adsorbed on the charcoal adsorption sites. It was reported that heavy metals in solution form hydrates with diameters of 10-18 $\AA[15,16]$. Higher concentrations of heavy metals contained in the solution result in a larger amount of heavy metal ion molecules. Therefore, the concentration of the adsorption solution may be a reason for the decrease in adsorption rate. Moreover, it is considered that the occupied area and the electrostatic repulsion between the heavy metals remarkably influence this decrease. These results indicate that simultaneous adsorption of multiple heavy metals is expected when the heavy metal concentration in the solution is low. Conversely, cases of high concentration should consider the adsorbed volume by charcoal per $1 \mathrm{~g}$ and the combination of heavy metal type and multiple heavy metal concentration. To approach practical application in the presence of several heavy metals, the concentration of heavy metals in solution should be determined to enable to $\mathrm{Cd}$ adsorption.

Table 3. Initial concentrations of solutions in experiments 1 (Unit: mg $\mathrm{L}^{-1}$ )

\begin{tabular}{|c|c|c|c|c|}
\hline Concentration level & $\mathrm{Cd}$ & $\mathrm{Cu}$ & $\mathrm{Zn}$ & $\mathrm{Pb}$ \\
\hline Low & 0.2 & 0.2 & 0.5 & 0.02 \\
\hline High & 1 & 10 & 10 & 2 \\
\hline Medium & 0.5 & 5 & 5 & 1 \\
\hline
\end{tabular}

\subsection{Cd re-elution (Experiment 2)}

The concentrations of $\mathrm{Cd}$ and $\mathrm{Cu}$ in the re-elution water from two types of the used charcoal are shown in Figures 3 (a) and (b). Water with a $\mathrm{pH}$ of 1.5 could remarkably elute $\mathrm{Cd}$ from both pollutant charcoals. In particular, the $\mathrm{Cd}$ re-elution rate was higher from the used charcoal with $\mathrm{Cd} / \mathrm{Cu}$ (Figure 3 (b)) at nearly $100 \%$ from that with $\mathrm{Cd}$ at $65 \%$ (Figure 4(a)).

The Cd re-elution rates decreased dramatically for both the charcoal types used, when in contact with water having a $\mathrm{pH}$ of 3.5 or more. The re-elution rate for $\mathrm{Cd}$ was $7-8 \%$, and that for $\mathrm{Cu}$ was approximately $0.1 \%$. Increasing the $\mathrm{pH}$ level resulted in decreased $\mathrm{Cd}$ re-elution rates, which indicates that used charcoal cannot be re-eluted unless exposed to strongly acidic water. Water at $\mathrm{pH}$ of 4.5 (equivalent to acidic rain) yielded re-elution rates of $0.8-1.6 \%$ from both types of charcoal. The $\mathrm{Cd}$ re-elution rate with distilled water was approximately $1 \%$.

The results of Experiment 2 showed similar characteristics for heavy metal elution by water with a $\mathrm{pH}$ of less than 2 from ferrite products used to treat polluted with heavy metal ions [7]. Moreover, these results nearly corresponded with those reported by Fujiwara et al. [17] in which a re-elution test was conducted with bamboo charcoal adsorption of $\mathrm{Zn}$ by strongly acidic water. In that experiment, the $\mathrm{Zn}$ re-elution rate was $90 \%$ for water with a pH of 2 and less than $20 \%$ for that with a pH of 4 , indicating a remarkable decrease. Such acidic treatment can re-elute heavy metals ions of hydroxide heavy metals remaining in the adsorbent $[5,6]$. The similar results obtained in Experiment 2 indicated that the mechanisms for heavy metal re-elution from charcoal were similar to those of ferrites. Moreover, the acidic treatment may have caused changes in the surface charges of the used charcoal. Machida et al. [18] reported that heavy metals ions present in solutions with large $\mathrm{pH}$ ranges are altered by the $\mathrm{pH}$ level of the solution, as are their formations. The surfaces of activated carbon are altered by the $\mathrm{pH}$ of the solution in a similar manner. Therefore, it is considered that the surfaces of the used charcoal in this study and the formation of heavy metal ions in the solution were altered by the $\mathrm{pH}$ of the solution, thereby changing the adsorption/desorption rates.

The results obtained in Experiment 2 suggest that even if the charcoal were in contact with acidic rainfall, the potential of re-elution from the used charcoal after use in situ would not be likely. On the contrary, the charcoal used as an adsorbent to $\mathrm{Cd}$ in situ may be disposed of after separation of the heavy metals by acid treatment for detoxification. 


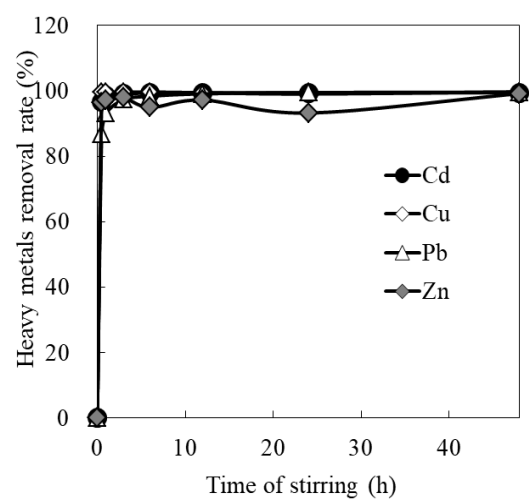

(a) Low concentration

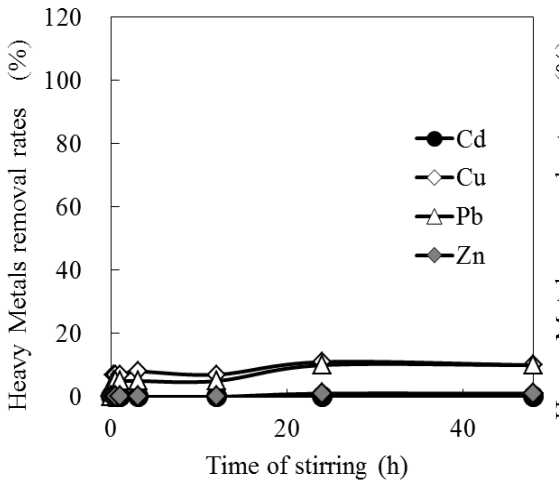

(b) High concentration

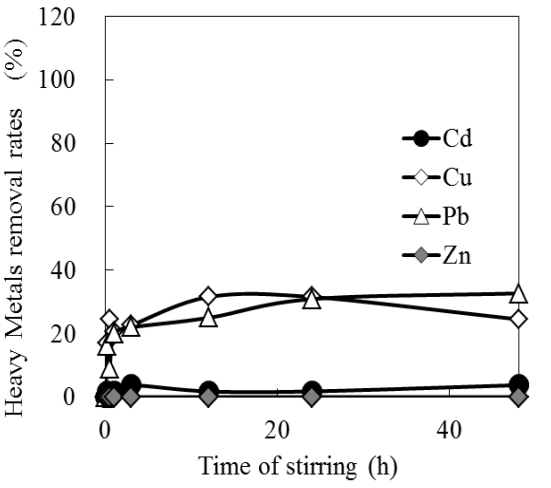

(c) Medium concentration

Figure 2. Time variations of heavy metal removal rate for concentrations levels of solutions in Experiment 2: (a) low concentration, (b) high concentration, and (c) medium concentration.

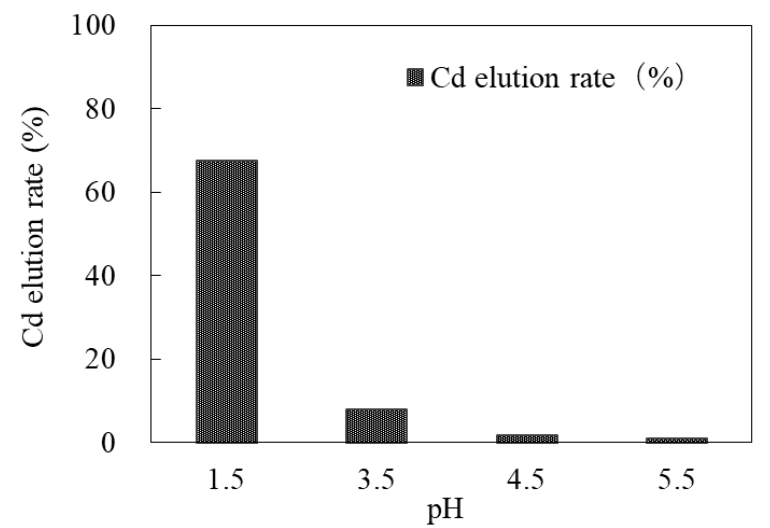

(a) Used charcoal (Cd)

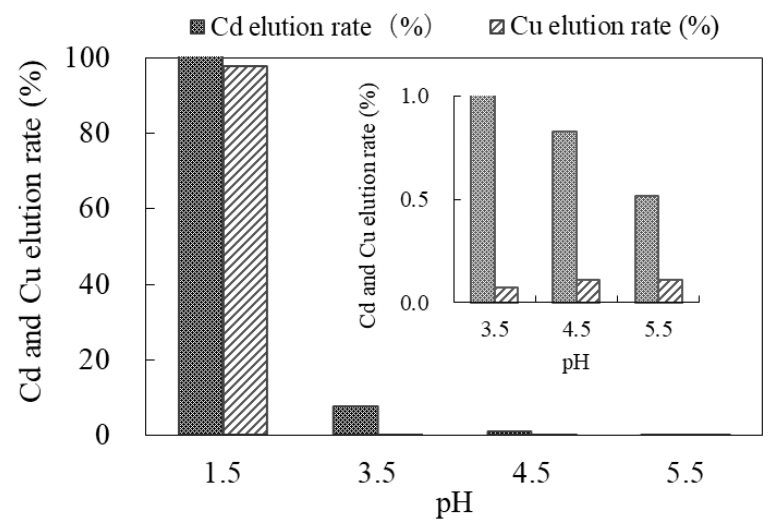

(b) Used charcoal $(\mathrm{Cd} / \mathrm{Cu})$

Figure 3. Re-elution rates for acidic solutions: (a) $\mathrm{Cd}$ re-elution from used charcoal $(\mathrm{Cd})$; (b) $\mathrm{Cd}$ and $\mathrm{Cu}$ re-elution from used charcoal $(\mathrm{Cd} / \mathrm{Cu}$ ).

\subsection{Column Experiments for Application to Soil (Experiment 3)}

The elution water from the columns was sampled every $24 \mathrm{~h}$ for 3 consecutive days immediately after starting Experiment 3. The $\mathrm{Cd}$ re-elution rates per $100 \mathrm{~mL}$ volume in sample water for rainfall intensities of $10 \mathrm{~mm} \mathrm{~h}^{-1}$ and $100 \mathrm{~mm} \mathrm{~h}^{-1}$ are shown in Figures 4 (a) and (b), respectively.

Regardless of soil water conditions, all rates of $\mathrm{Cd}$ re-elution from the used charcoal were less than $0.1 \%$ (Figure 4). The re-elution rates under nonsaturated conditions were higher than those under saturated conditions (Figures 4 (a) and (b)). That is, the magnification ratio of the rate of $\mathrm{Cd}$ re-elution in the nonsaturation case was approximately twice that of saturation with $10 \mathrm{~mm} \mathrm{~h}^{-1}$ rainfall intensity and approximately 7 times that with $100 \mathrm{~mm} \mathrm{~h}^{-1}$ rainfall intensity. Therefore, $\mathrm{Cd}$ was not easily eluted under saturation conditions by higher rainfall intensity or under the nonsaturated conditions by lower rainfall intensity. These indicate that $\mathrm{Cd}$ can be accumulated in the environment if a considerable amount is re-eluted from nonsaturated soil by a rainfall of high intensity.

Moreover, the elution water from the same columns after 1 month were sampled every $24 \mathrm{~h}$ for 3 consecutive days; results are shown in Figure 5. We have examined the cases of rainfall intensities for nonsaturated soil because of the concern of $\mathrm{Cd}$ re-elution under such conditions. The results indicated that the $\mathrm{Cd}$ re-elution rates were less than those observed after starting Experiment 3 for both rainfall intensities (Figures 5 (a) and (b)). Additionally, it was confirmed that the re-elution water sampled after two and three months did not contain Cd (Figures 6 (a) and (b)).

According to the results of Experiment 3, it is believed that the oxidation-reduction potential was lowered under saturation conditions. Therefore, it is considered that the form of $\mathrm{Cd}$ re-eluted from charcoal in soil pore water could form compounds such as cadmium sulfide $(\mathrm{CdS})$, which could lead to a decrease in the aqueous $\mathrm{Cd}$ state in sample water [2]. Moreover, it is believed that $\mathrm{Cd}$ re-elution from charcoal was suppressed because the re-eluted $\mathrm{Cd}$ from charcoal was re-adsorbed onto the soil grains.

A three-month monitoring period indicated a gradual decrease in $\mathrm{Cd}$ re-elution, which amounted to $0 \%$ by the end of the period. Therefore, concerns about the release of accumulated elution into the environment are resolved. 


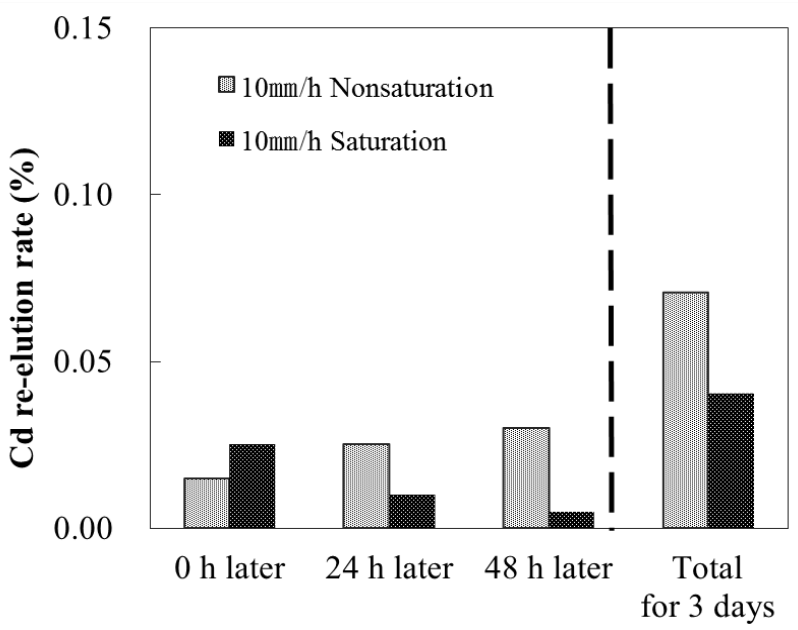

(a) $10 \mathrm{~mm} \mathrm{~h}^{-1}$
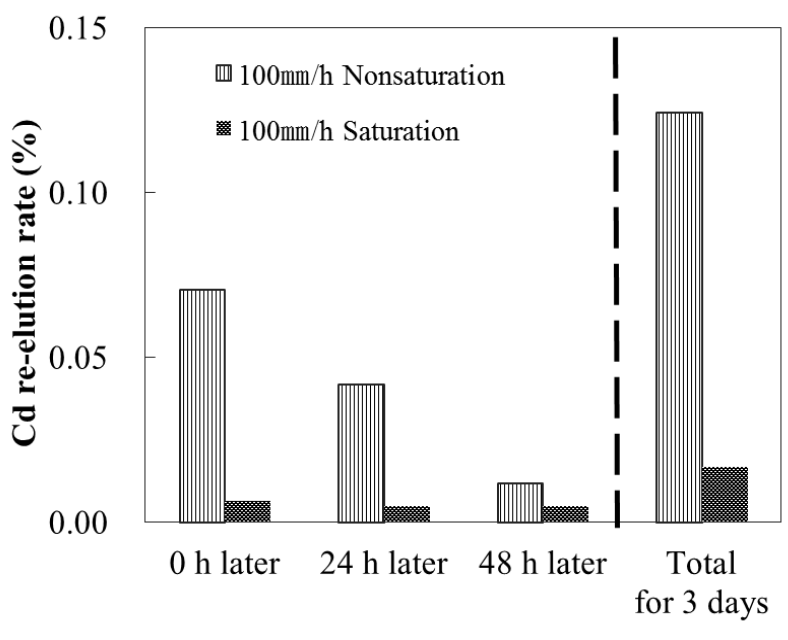

(b) $100 \mathrm{~mm} \mathrm{~h}^{-1}$

Figure 4. Elution rate from used charcoal measured immediately after beginning Experiment 3 relative to rainfall intensities of (a) $10 \mathrm{~mm} \mathrm{~h}^{-1}$ and (b) $100 \mathrm{~mm} \mathrm{~h}^{-1}$.

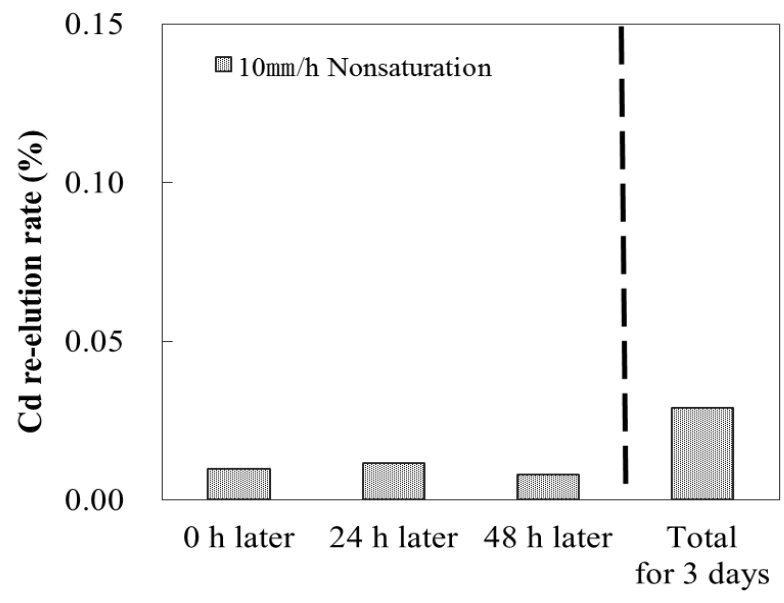

(a) $10 \mathrm{~mm} \mathrm{~h}^{-1}$

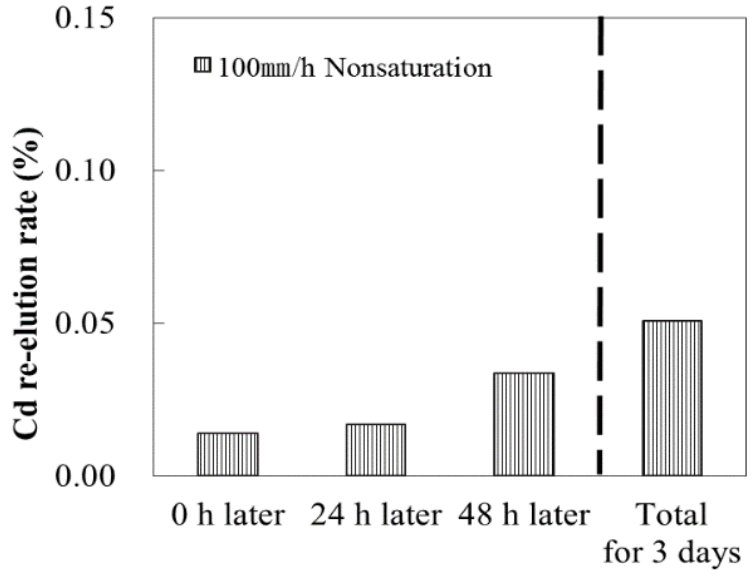

(b) $100 \mathrm{~mm} \mathrm{~h}^{-1}$

Figure 5. Elution rate from used charcoal measured one month after beginning Experiment 3 relative to rainfall intensities of (a) $10 \mathrm{~mm} \mathrm{~h}^{-1}$ and (b) 100 $\mathrm{mm} \mathrm{h}^{-1}$

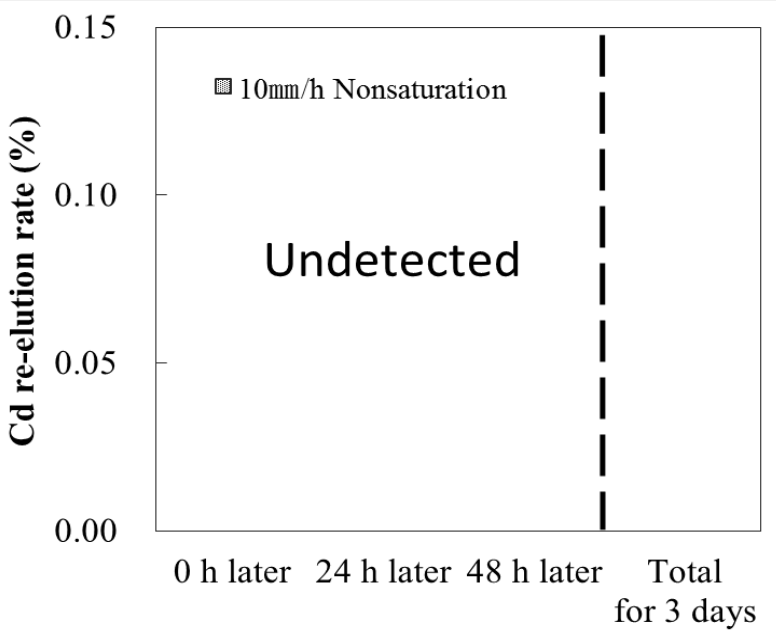

(a) $10 \mathrm{~mm} \mathrm{~h}^{-1}$

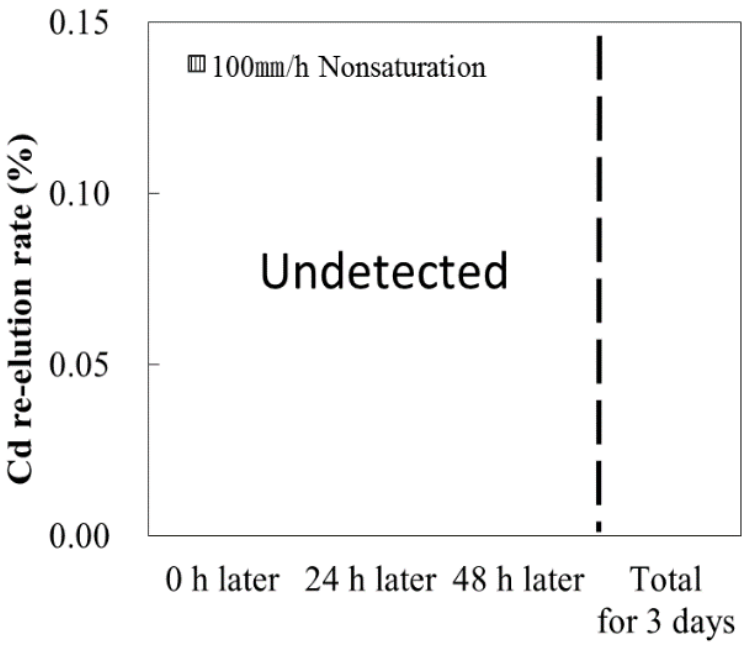

(b) $100 \mathrm{~mm} \mathrm{~h}^{-1}$

Figure 6. Elution rate from used charcoal measured two and three months after beginning Experiment 3 relative to rainfall intensities of (a) $10 \mathrm{~mm} \mathrm{~h}^{-1}$ and (b) $100 \mathrm{~mm} \mathrm{~h}^{-1}$. 


\section{Conclusions}

In this study, charcoal was examined for practical usage in the field as a remediation material for $\mathrm{Cd}$ contamination by conducting three evaluation experiments. The results are summarized in the following points:

(1) In the presence of $\mathrm{Cd}$ in solution along with multiple heavy metals, a simultaneous adsorption of all such heavy metals was observed, if the solution has a relatively low concentration level. Further, the selective adsorption characteristics of the charcoal depend on the combination of types and concentrations of heavy metals contained in the solution.

(2) If the $\mathrm{pH}$ level of the solution in contact with the used charcoal is more than 3.5 , the re-elution rate is suppressed to $10 \%$ or less. Thus, it is suggested that the heavy metal re-elution rate can decrease if the solution is directly exposed to rain water of 6$7 \mathrm{pH}$ or acidic rain of $4.5 \mathrm{pH}$. The normal processing of used charcoal is possible after contact with a strong acid with a $\mathrm{pH}$ of less than 1.5 to separate the heavy metals from the charcoal.

(3) If the charcoal remains in environmental soil for a lengthy period, the $\mathrm{Cd}$ re-elution rate is less than $0.1 \%$, according to the column experiment results, and the contaminant was not detected after two and three months. Therefore, it is suggested that even if the used charcoal were to remain in the environment for a long period, concerns of environmental recontamination by $\mathrm{Cd}$ re-elution from used charcoal are allayed.

The results of these evaluation tests of charcoal in this study validate its practical application. As topics for future research, the shape of the charcoal to be utilized must be determined, and the possibility of utilization in places other than agricultural land should be examined. A future goal is to achieve the construction of a regional resource recycling system. Local biomass resources to be discarded as waste should be treated as environmental materials used to restore regions such as agricultural, mining, and manufacturing areas. Therefore, it is expected that charcoal utilization will be employed in Japan and in other countries as a countermeasure for similar pollution problems.

\section{REFERENCES}

[1] Murakami M., Ae N., Ishikawa S. Phytoextraction of cadmium by rice (Oryza sativa L.), soybean (Glycine max (L.) Merr.), and maize (Zea mays L.), Environ. Pollut., vol.145, 96-103, 2007.

[2] Ibararaki T. Kuroyanagi N., Murakami M. Practical phytoextraction in cadmium-polluted paddy fields using a high cadmium accumulating rice plant cultured by early drainage of irrigation water, Soil Sci. Plant Nutr., vol.55, No.3, 421-427, 2009.

[3] Maejima Y., Makino T., Takano H., Kamiya T., Sekiya N., Itou $\mathrm{T}$. Remediation of cadmium-contaminated paddy soils by washing with chemicals: Effect of soil washing on cadmium uptake by soybean, Chemosphere, vol.67, 748754, 2007.

[4] Alfaraa A., Frackowiakb E., Béguina F. The HSAB concept as a means to interpret the adsorption of metal ions onto activated carbons. Appl. Surf. Sci., vol.228, 84-92, 2004.

[5] Kaneko K., Takei K., Tamura Y., Kanzaki T., Katsura T. The formation of the Cd-bearing ferrite by the air oxidation of an aqueous suspension, Bull. Chem. Soc. Jpn., vol.52, No.4, 1080-1085, 1979.

[6] Kanzaki T. Nakajima J., Tamaura Y., Katsura T. Formation of Zn-bearing ferrite by air oxidation of aqueous suspension, Bull. Chem. Soc. Jpn., vol.54, 135-137, 1981.

[7] Kondo M., Nakashima N., Hirasawa T. Characteristics of heavy metal dissolution from $\mathrm{Zn}, \mathrm{Cd}$, and $\mathrm{Mn}$ bearing ferrites, J. Jpn. Soc. Water Environ., vol.15, No.5, 313-320, 1992.

[8] Komkiene J., Baltrenaite E. Biochar as adsorbent for removal of heavy metal ions [Cadmium(II), Copper(II), Lead(II), Zinc(II)] from aqueous phase, Int. J. Environ. Sci. Technol., vol.13, 471-481, 2016.

[9] Li H., Dong X., da Silva E.B., de Oliveira L. M., Chen Y, Ma L.Q. Mechanisms of metal sorption by biochars: Biochar characteristics and modifications, Chemosphere, vol.178, 466-478, 2017.

[10] He T., Menng J., Chen W., Liu Z., Cao T., Cheng X., Huang Y., Yang X. Effects of biochar on cadmium accumulation in rice and cadmium fractions of Soil: A three-year pot experiment, BioResources, vol.12, No.1, 622-642, 2017.

[11] Wang S., Xu Y., Norbu N., Wang Z. Remediation of biochar on heavy metal polluted soils, Earth Envion. Sci. vol.108, 042113, 2018.

[12] Xu C., Wen D., Zhu Q., Zhu H., Zhang Y. Effect of peanut shell biochar on the adsorption of Cd(II)by paddy soil. Bull. Envion. Contam. Toxicol, vol.98, 413-419, 2017.

[13] Miura A., Shiratani E., Hamada K., Hitomi T., Kubota T. Control of cadmium accumulation in topsoil and crops from contaminated farmland, Desalin. Water Treat., vol.19, 1-6, 2010 .

[14] Machida M., Aikawa M., Tatsumoto H. Prediction of simultaneous adsorption of $\mathrm{Cu}$ (II) and $\mathrm{Pb}$ (II) onto activated carbon by conventional Langmuir type equations, J. Hazard Mater., vol.120, No.1-3, 271-275, 2005.

[15] Dias J. M., Alvim-Ferraz M. C. M., Almeida M. F., Rivera-Utrilla J., Sánchez-Polo M. Waste materials for activated carbon preparation and its use in aqueous-phase treatment: A review, J. Environ. Manage. vol.85, 833-846, 2007.

[16] Moreno-Castilla C., Álvarez-Merino M. A., Pastrana-Martínez L. M., López-Ramón M. V. Adsorption mechanisms of metal cations from water on oxidized 
carbon surface, J. Colloid Interf. Sci., vol. 345, 461-466, 2010.

[17] Fujiwara, S., Shima, K., Chiba, K. Heavy metal adsorption ability of bamboo charcoal and effect as a mulching material,
J. Jpn. Soc. Reveget. Tech., vol.30, No.1, 39-44, 2004.

[18] Machida M., Amano Y., Aikawa M. Adsorptive removal of heavy metal ions by activated carbons, Tanso, vol.247, 6269, 2011. 